\title{
Polymer Foam Flow in Porous Media under Different Injection Modes
}

\author{
Wei Zhao, Haiqing Cui, Keliang Wang \\ Key Laboratory of Enhanced Oil and Gas Recovery of Ministry of Education, Northeast Petroleum University, \\ Daqing, China \\ Email: zhaoweinepu@163.com
}

Received 13 July 2015; accepted 17 August 2015; published 20 August 2015

Copyright $@ 2015$ by authors and Scientific Research Publishing Inc.

This work is licensed under the Creative Commons Attribution International License (CC BY).

http://creativecommons.org/licenses/by/4.0/

(c) ()

\begin{abstract}
The mathematical models of the flow of polymer foam in porous media under three injection modes are established and the relevant numerical calculation methods are given. The profiles of the liquid phase saturation, the pressure drop and the number density of the flowing HPAM foam in artificial sandstone cores with the dimensionless distance under three injection modes are numerically calculated and analyzed. The results show that, compared with the injection mode 2 and 3, HPAM foam flows in a piston-like fashion in the artificial sandstone core under the injection mode 1 and produces the biggest pressure drop. Obviously, the flood efficiency is the highest under the injection mode 1.
\end{abstract}

\section{Keywords}

Injection Mode, Polymer Foam, Porous Media, Mathematical Model, Numerical Calculation

\section{Introduction}

It can provides the necessary theoretical foundation for polymer flooding engineering design through researching the flow of the polymer foam in porous media under different injection modes. Shan, et al. [1] given an optimal foam-injection strategy in homogeneous reservoirs with a variety of foam models by using simulation. Stevens, et al. [2] presented an overview of the operating plan for $\mathrm{CO}_{2}$ foam injection and the details of the $\mathrm{CO}_{2}$ foam injection schedule and design criteria in the East Vacuum Grayburg San Andres Unit. Hou, et al. [3] compared three main injection modes, including co-injection of gas and solution, alternative injection of gas and solution, and direct injection of foam and pointed that the direct injection of foam was the most effective mode and the alternative injection of gas and solution is the poorest. Li, et al. [4] experimentally studied the use of additives to enhance foam properties and the factors affecting blocking performance such as injection model, gas 
liquid ratio, and alternate slug, etc. Harsenhorst, et al. [5] illustrated with a model fit by Rossen, et al. [6] to data of Persoff, et al. [7], a fit specifically designed for a hypothetical surfactant-alternating-gas (SAG) application. The mathematical models of the flow of polymer foam in porous media under three injection modes will be established and the numerical calculation methods will be given in this paper. According to the mathematical models and the numerical calculation methods metioned above, the profiles of the liquid phase saturation, the pressure drop and the number density of the flowing HPAM foam in artificial sandstone core under three injection modes metioned above will be numerically calculated and analyzed.

\section{Injection Modes}

There are three injection modes for the porous media filled with polymer-surfactant aqueous solution,that is, the injection mode 1 which is the co-injection of polymer surfactant aqueous solution and air into the porous media, the injection mode 2 which is the injection of air into the porous media and the injection mode 3 which is the injection of polymer surfactant aqueous solution into the porous media.

\section{Mathematical Models}

According to the mass and the population balance principles, the mathematical models of polymer foam flow in porous media under different injection modes can be obtained.

\subsection{Injection Mode 1}

The mathematical model of the flow of polymer foam in porous media under the injection mode 1 is as follows [8]-[11].

The mass balance equations

$$
\begin{aligned}
& \frac{\partial\left(\phi \rho_{\mathrm{p}} S_{\mathrm{p}}\right)}{\partial t}=\frac{\partial}{\partial x}\left(\rho_{\mathrm{p}} \frac{K K_{\mathrm{rp}}}{\mu_{\mathrm{p}}}\left(\frac{\partial P_{\mathrm{p}}}{\partial x}\right)\right)+q_{\mathrm{p}} \\
& \frac{\partial\left(\phi \rho_{\mathrm{g}} S_{\mathrm{g}}\right)}{\partial t}=\frac{\partial}{\partial x}\left(\rho_{\mathrm{g}} \frac{K K_{\mathrm{rg}}}{\mu_{\mathrm{g}}}\left(\frac{\partial P_{\mathrm{g}}}{\partial x}\right)\right)+q_{\mathrm{g}}
\end{aligned}
$$

the population balance equations

$$
\begin{gathered}
\frac{\partial\left(\phi\left(S_{\mathrm{f}} n_{\mathrm{f}}+S_{\mathrm{t}} n_{\mathrm{t}}\right)\right)}{\partial t}=-\frac{\partial\left(u_{\mathrm{f}} n_{\mathrm{f}}\right)}{\partial x}+\phi S_{\mathrm{g}}\left(k_{1} v_{\mathrm{f}}^{1 / 3} v_{\mathrm{p}}-k_{-1}^{o} \frac{\left(1-S_{\mathrm{p}}\right)}{\left(S_{\mathrm{p}}-S_{\mathrm{pc}}\right)} v_{\mathrm{f}} n_{\mathrm{f}}\right)+H_{\mathrm{b}} \\
K_{\mathrm{rp}}=k_{\mathrm{rp}}^{\mathrm{o}}\left(\frac{S_{\mathrm{p}}-S_{\mathrm{pr}}}{1-S_{\mathrm{pr}}}\right)^{f} \\
K_{\mathrm{rg}}=k_{\mathrm{rg}}^{\mathrm{o}}\left(X_{\mathrm{f}}\left(1-\frac{S_{\mathrm{p}}-S_{\mathrm{pr}}}{1-S_{\mathrm{pr}}}\right)\right)^{g} \\
\mu_{\mathrm{p}}=\left(K_{\mathrm{c}}\left[\frac{3 n+1}{n+1} \frac{1}{\sqrt{8 c^{\prime} K \phi}}\left(-K K_{\mathrm{rp}}\left(\frac{P_{\mathrm{g}}}{P_{\mathrm{ga}}} \frac{\partial P_{\mathrm{p}}}{\partial x}\right)\right)\right]^{n-1}\right)^{\frac{1}{n}} \\
\mu_{\mathrm{g}}=\mu_{\mathrm{g} 0}+\frac{\alpha n_{\mathrm{f}}}{v_{\mathrm{f}}^{c}}=\mu_{\mathrm{f}}
\end{gathered}
$$


the assistant equations

$$
\begin{gathered}
P_{\mathrm{c}}=P_{\mathrm{g}}-P_{\mathrm{p}} \\
P_{\mathrm{c}}=\sigma \sqrt{\frac{\phi}{K}} J\left(S_{\mathrm{p}}\right) \\
S_{\mathrm{p}}+S_{\mathrm{g}}=1 \\
n_{\mathrm{t}}=\frac{K_{\mathrm{f}} A_{\mathrm{f}} n_{\mathrm{f}}}{1+K_{\mathrm{f}} n_{\mathrm{f}}}
\end{gathered}
$$

the initial conditions

$$
\begin{array}{r}
P_{\mathrm{p}}(x, 0)=P_{\mathrm{pi}} \\
P_{\mathrm{g}}(x, 0)=0 \\
S_{\mathrm{p}}(x, 0)=1 \\
S_{\mathrm{g}}(x, 0)=0 \\
n_{\mathrm{f}}(x, 0)=0 \\
n_{\mathrm{t}}(x, 0)=0
\end{array}
$$

the boundary conditions

$$
\begin{gathered}
-\left.\frac{K \cdot K_{\mathrm{rp}}}{\mu_{\mathrm{p}}} \frac{\partial P_{\mathrm{p}}}{\partial x}\right|_{t=t, x=0}=u_{\mathrm{p} i} \\
-\left.\frac{K \cdot K_{\mathrm{rg}}}{\mu_{\mathrm{g}}} \frac{\partial P_{\mathrm{g}}}{\partial x}\right|_{t=t, x=0}=u_{\mathrm{g} i} \\
P_{\mathrm{p}}(L, t)=P_{0} \\
P_{\mathrm{g}}(L, t)=P_{0} \\
n_{\mathrm{f}}(0, t)=n_{\mathrm{f}}(L, t)=0 \\
n_{\mathrm{t}}(0, t)=n_{\mathrm{t}}(L, t)=0
\end{gathered}
$$

where $\phi$ the porosity; $\rho_{\mathrm{p}}$ the liquid phase mass density, $\mathrm{kg} / \mathrm{m}^{3} ; S_{\mathrm{p}}$ the saturation of liquid phase; $K$ the permeability of porous media, $\mathrm{m}^{2} ; K_{\mathrm{rp}}$ the liquid phase relative permeability; $\mu_{\mathrm{p}}$ the apparent viscosity of liquid phase, $\mathrm{Pa} \cdot \mathrm{s} ; P_{\mathrm{p}}$ the pressure of liquid phase, $\mathrm{Pa} ; q_{\mathrm{p}}$ the source-sink term of liquid phase, $\mathrm{kg} / \mathrm{m}^{3}$; $\rho_{\mathrm{g}}$ the gas mass density, $\mathrm{kg} / \mathrm{m}^{3} ; S_{\mathrm{g}}$ the saturation of gas phase; $K_{\mathrm{rg}}$ the gas phase relative permeability; $\mu_{\mathrm{g}}$ the gas viscosity, $\mathrm{Pa} \cdot \mathrm{s} ; P_{\mathrm{g}}$ the pressure of gas phase, $\mathrm{Pa} ; q_{\mathrm{g}}$ the source-sink term of gas phase, $\mathrm{kg} / \mathrm{m}^{3} ; S_{\mathrm{f}}$ the gas phase saturation of flowing foam; $n_{\mathrm{f}}$ the number density of flowing foam, $\mathrm{m}^{-3} ; S_{\mathrm{t}}$ the gas phase saturation of trapped foam; $n_{\mathrm{t}}$ the number density of trapped foam, $\mathrm{m}^{-3} ; u_{\mathrm{f}}$ the velocity of the flowing foam in porous media, $\mathrm{m} / \mathrm{s} ; k_{1}$ the foam generation coefficient, $\mathrm{m}^{1 / 3} \cdot \mathrm{s}^{-13 / 3} ; v_{\mathrm{f}}$ the local interstitial velocity of flowing foam, $\mathrm{m} / \mathrm{s} ; v_{\mathrm{p}}$ the local interstitial liquid velocity, $\mathrm{m} / \mathrm{s} ; k_{-1}^{o}$ the foam coalescence coefficient, $\mathrm{m}^{-1} ; S_{\mathrm{pc}}$ the liquid phase saturation relevant to the limiting capillary pressure; $H_{\mathrm{b}}$ the source-sink term for foam bubbles in units of number per unit volume per unit time, $\mathrm{m}^{-3} ; k_{\mathrm{rp}}^{o}$ the liquid relative permeability where $S_{\mathrm{p}}=S_{\mathrm{pr}} ; S_{\mathrm{pr}}$ the connate liquid phase saturation; $f$ the index; $k_{\mathrm{rg}}^{0}$ the gas relative permeability where $S_{\mathrm{p}}=S_{\mathrm{pr}} ; X_{\mathrm{f}}$ the fraction of the gas phase flow rate; $g$ the index; $\rho_{\mathrm{ga}}$ the air density under standard atmosphere, $\mathrm{kg} / \mathrm{m}^{3} ; P_{\mathrm{ga}}$ the pressure under standard atmosphere, $\mathrm{Pa} ; n$ flow behavior index of liquid phase; $K_{c}$ the consistency coefficient of liquid phase, $\mathrm{Pa} \cdot \mathrm{s}^{n} ; c^{\prime}$ the pore tortuosity; $\mu_{\mathrm{g} 0}$ the initial gas phase viscosity, $\mathrm{Pa} \cdot \mathrm{s} ; \alpha$ the constant of proportionality dependent primarily on the surfactant 
system, $\mathrm{Pa} \cdot \mathrm{s}^{2 / 3} \cdot \mathrm{m}^{10 / 3} ; \mathrm{c}$ the index; [12] [13] $\mu_{\mathrm{f}}$ the foam effective viscosity, $\mathrm{Pa} \cdot \mathrm{s} ; P_{\mathrm{c}}$ the capillary pressure, Pa; $\sigma$ the equilibrium surface tension, $\mathrm{N} / \mathrm{m} ; J\left(S_{\mathrm{p}}\right)$ Leverett $J$ function; $K_{\mathrm{f}}, A_{\mathrm{f}}$ are the bubble trapped parameters; $P_{\mathrm{pi}}$ is the initial liquid phase pressure, $\mathrm{Pa} ; u_{\mathrm{pi}}$ the injection velocity of liquid phase, $\mathrm{m} / \mathrm{s}$; $u_{\mathrm{gi}}$ the injection velocity of gas phase, $\mathrm{m} / \mathrm{s} ; L$ the length of porous media, $\mathrm{m} ; P_{0}$ the backpressure, $\mathrm{Pa}$.

\subsection{Injection Mode 2}

Under the injection mode 2, where the Formula (19) of the mathematical model of the flow of the polymer foam in porous media under the injection mode 1 changes as follow

$$
-\left.\frac{K \cdot K_{\mathrm{rp}}}{\mu_{\mathrm{p}}} \frac{\partial P_{\mathrm{p}}}{\partial x}\right|_{t=t, x=0}=0
$$

the mathematical model of the flow of the polymer foam in porous media consists of Formula (1)-(18), (25), (20)-(24).

\subsection{Injection Mode 3}

Under the injection mode 3, the mathematical model of the flow of the polymer foam in porous media consists of Formula (1), (13), (15), (19) and (21).

\section{Numerical Calculation Methods}

The mathematical models of the flow of polymer foam in porous media under three injection modes are numerically calculated by the finite difference method [9] [14] [15].

For the Injection mode 1 and the injection mode 2, the mass balance Equations (1) and (2) are solved by IMPES (Implicit Pressure Explicit Saturation) method, and the population balance Equation (3) is solved by TVD (Total Variation Diminish) three order method. For the Injection mode 3, the mass balance Equation (1) is solved by IM (Implicit Method).

\section{Numerical Calculations and Analyses}

The flow of the foam of the $0.015 \mathrm{wt} \%$ HPAM, $0.200 \mathrm{wt} \%$ FL-605 and $0.830 \mathrm{wt} \% \mathrm{NaCl}$ HPAM solution and the air under different injection modes in the artificial sandstone core are numerically calculated and analyzed.

\subsection{Basic Data}

The basic data of the three injection modes are shows as Table 1 [8] [9].

\subsection{Injection Mode 1}

Under the injection mode 1 , the profiles of the liquid phase saturation $S_{\mathrm{p}}$, the pressure drop $\Delta P_{\mathrm{p}}$, the number density $n_{\mathrm{f}}$ of the flowing HPAM foam in the artificial sandstone core show as Figures 1-3.

In Figure 1, under the injection mode 1, the liquid phase saturation $S_{\mathrm{p}}$ of HPAM foam at the flow front appears to be steep and sharp, the liquid phase saturation $S_{\mathrm{p}}$ of the upstream of the flow front is about 0.38 , and 1.00 of the downstream. The gas phase breaks through at about dimensionless time $0.80 \mathrm{PV}$. The liquid phase saturation $S_{\mathrm{p}}$ at steady state is about 0.38 . HPAM foam flows in a piston-like fashion in the artificial sandstone core. After HPAM foam flow front passes a particular location of the core, the liquid phase saturation $S_{\mathrm{p}}$ changes very little.

In Figure 2, under the injection mode 1, the pressure drop $\Delta P_{\mathrm{p}}$ of the upstream of HPAM foam flow front decreases along with the dimensionless distance $x / L$ increasing, the pressure drop $\Delta P_{\mathrm{p}}$ of the downstream of HPAM foam flow front is zero. The pressure drop $\Delta P_{\mathrm{p}}$ doesn't increase up to $948.99 \mathrm{kPa}$ along with dimensionless time $P V$ elapsing until about $2 \mathrm{PV}$.

In Figure 3, under the injection mode 1, there is the flow front of HPAM foam in the artificial sandstone core. The number density $n_{\mathrm{f}}$ of flowing foam reaches the peak value at the flow front. The steady state profile of the 
Table 1. Basic data.

\begin{tabular}{|c|c|c|c|}
\hline & Injection mode 1 & Injection mode 2 & Injection mode 3 \\
\hline$\rho_{\mathrm{p}} /\left(\mathrm{kg} \cdot \mathrm{m}^{-3}\right)$ & 1000.09 & 1000.09 & 1000.09 \\
\hline$n$ & 0.9316 & 0.9316 & 0.9316 \\
\hline$K_{c} \times 10^{-2} /\left(\mathrm{Pa} \cdot \mathrm{s}^{n}\right)$ & 0.1359 & 0.1359 & 0.1359 \\
\hline$\rho_{\mathrm{ga}} \times 10^{-1} / \mathrm{kg} \cdot \mathrm{m}^{-3}$ & 11.03 & 11.03 & 0.00 \\
\hline$L / \mathrm{m}$ & 0.30 & 0.30 & 0.30 \\
\hline$K \times 10^{-12} / \mathrm{m}^{2}$ & 0.66 & 0.66 & 0.66 \\
\hline$\phi$ & 0.26 & 0.26 & 0.26 \\
\hline$c^{\prime}$ & 2.30 & 2.30 & 2.30 \\
\hline$k_{\mathrm{rp}}^{\circ}$ & 0.70 & 0.70 & 0.00 \\
\hline$k_{\mathrm{rg}}^{\circ}$ & 1.00 & 1.00 & 0.00 \\
\hline$f$ & 3.01 & 3.01 & 0.00 \\
\hline$g$ & 3.03 & 3.03 & 0.00 \\
\hline$S_{\mathrm{pr}}$ & 0.29 & 0.29 & 0.29 \\
\hline$S_{\mathrm{pc}}$ & 0.26 & 0.26 & 0.00 \\
\hline$\sigma \times 10^{-1} /(\mathrm{N} / \mathrm{m})$ & 0.33 & 0.33 & 0.00 \\
\hline$\mu_{\mathrm{g} 0} \times 10^{-4} / \mathrm{Pa} \cdot \mathrm{s}$ & 0.18 & 0.18 & 0.00 \\
\hline$\mu_{\mathrm{p} 0} \times 10^{-1} / \mathrm{Pa} \cdot \mathrm{s}$ & 0.01 & 0.01 & 0.01 \\
\hline$\alpha \times 10^{-14} / \mathrm{Pa} \cdot \mathrm{s}^{2 / 3} \cdot \mathrm{m}^{10 / 3}$ & 6.00 & 6.00 & 0.00 \\
\hline c & 0.33 & 0.33 & 0.00 \\
\hline$P_{0} / \mathrm{MPa}$ & 4.80 & 4.80 & 4.80 \\
\hline$P_{\mathrm{pi}} / \mathrm{MPa}$ & 4.80 & 4.80 & 4.80 \\
\hline$P_{\mathrm{ga}} / \mathrm{MPa}$ & 0.10 & 0.10 & 0.00 \\
\hline$u_{\mathrm{p}} /(\mathrm{m} / \mathrm{d})$ & 0.046 & 0.000 & 0.046 \\
\hline$u_{\mathrm{g}} /(\mathrm{m} / \mathrm{d})$ & 0.431 & 0.431 & 0.000 \\
\hline$k_{1} / \mathrm{m}^{1 / 3} \cdot \mathrm{s}^{-13 / 3}$ & 10.08 & 10.08 & 0.00 \\
\hline$k_{-1}^{o} / \mathrm{m}^{-1}$ & 57.84 & 57.84 & 0.00 \\
\hline
\end{tabular}

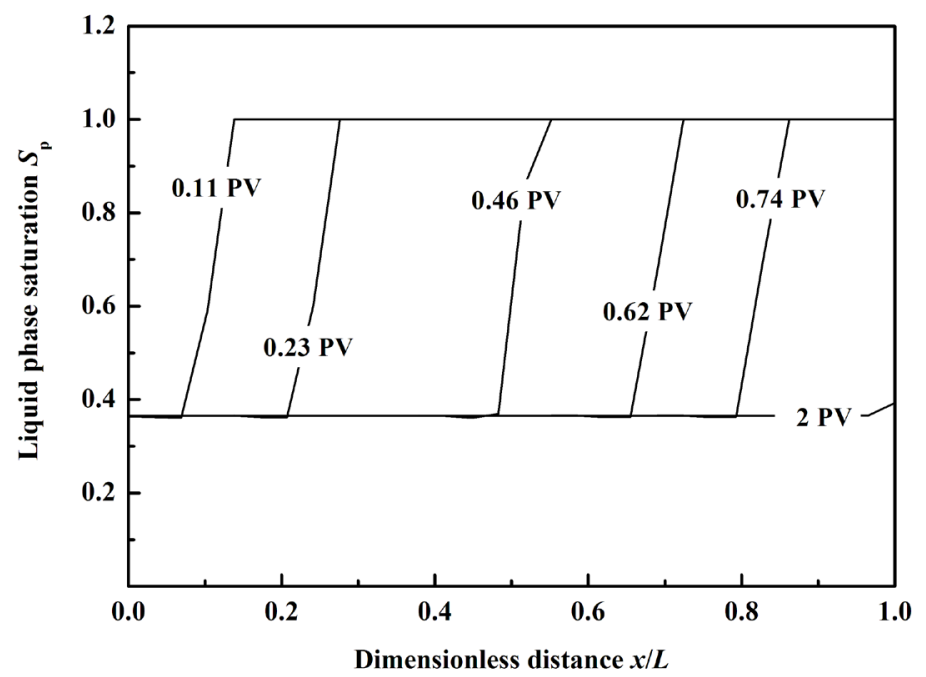

Figure 1. Profiles of the liquid phase saturation $S_{\mathrm{p}}$ under the injection mode 1. 


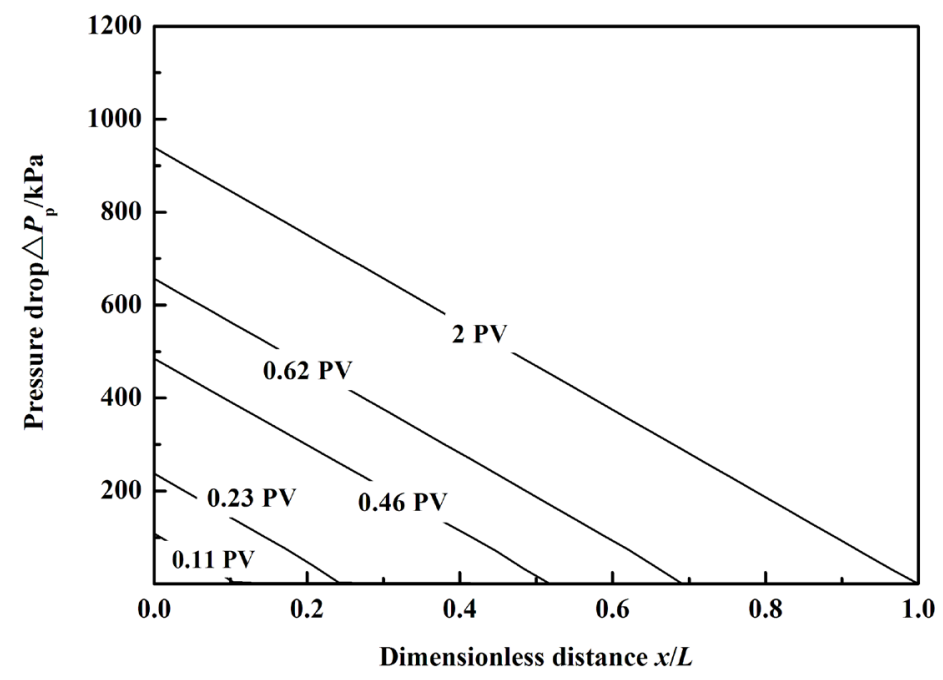

Figure 2. Profiles of the pressure drop $\Delta P_{\mathrm{p}}$ under the injection mode 1.

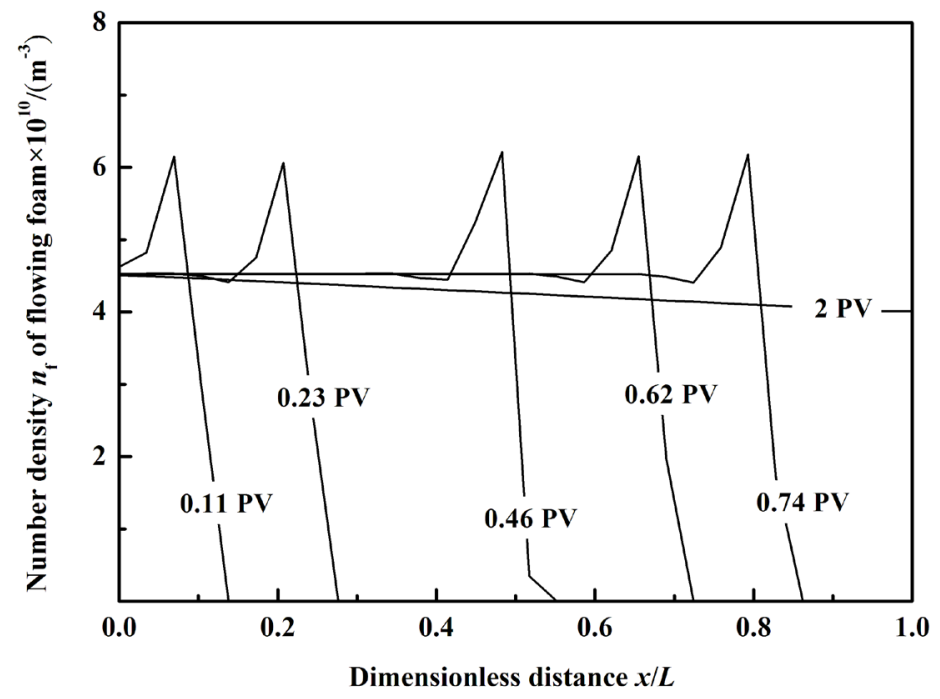

Figure 3. Profiles of the number density $n_{\mathrm{f}}$ of flowing foam under the injection mode 1.

number density $n_{\mathrm{f}}$ of flowing foam appears at $2 \mathrm{PV}$, after which the number density $n_{\mathrm{f}}$ of flowing foam decreases from the inlet to the outlet.

\subsection{Injection Mode 2}

Under the injection mode 2, the profiles of the liquid phase saturation $S_{\mathrm{p}}$, the pressure drop $\Delta P_{\mathrm{p}}$, the number density $n_{\mathrm{f}}$ of the flowing HPAM foam in the artificial sandstone core show as Figures 4-6.

In Figure 4, under the injection mode 2, the liquid phase saturation $S_{\mathrm{p}}$ of the upstream of HPAM foam flow front is about 0.32, the liquid phase saturation $S_{\mathrm{p}}$ at the flow front appears to be steep and sharp and the liquid phase saturation $S_{\mathrm{p}}$ of the downstream of the flow front is 1.00 , which is because the gas phase flow and the foam flow appear in the upstream of the flow front, the foam flow and the liquid phase flow appear in the upstream of the flow front under the injection mode 2.

In Figure 5, under the injection mode 2, the pressure drop $\Delta P_{\mathrm{p}}$ of the upstream of HPAM foam flow front is about $27 \mathrm{kPa}$, the pressure drop $\Delta P_{\mathrm{p}}$ at the flow front changes sharply and the pressure drop $\Delta P_{\mathrm{p}}$ of the 


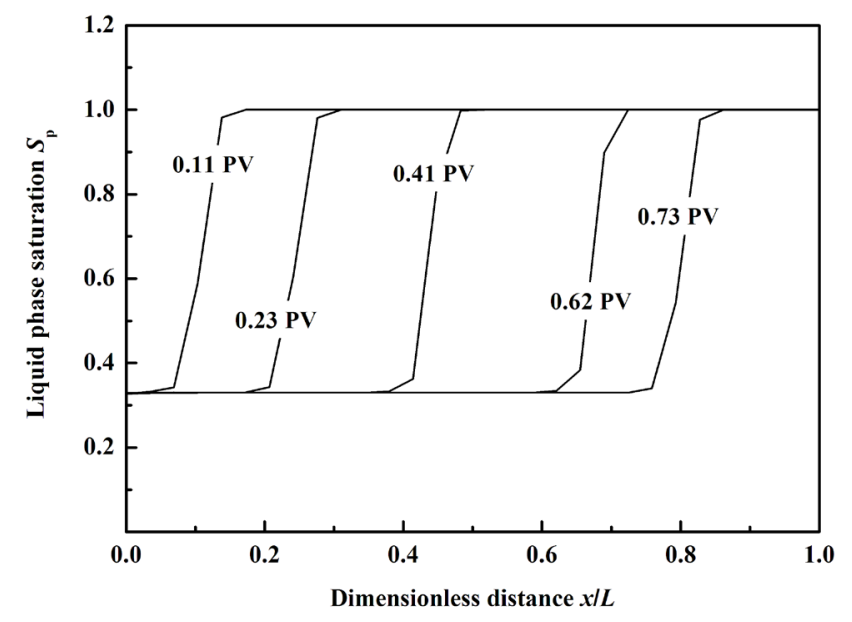

Figure 4. Profiles of the liquid phase saturation $S_{\mathrm{p}}$ under the injection mode 2 .

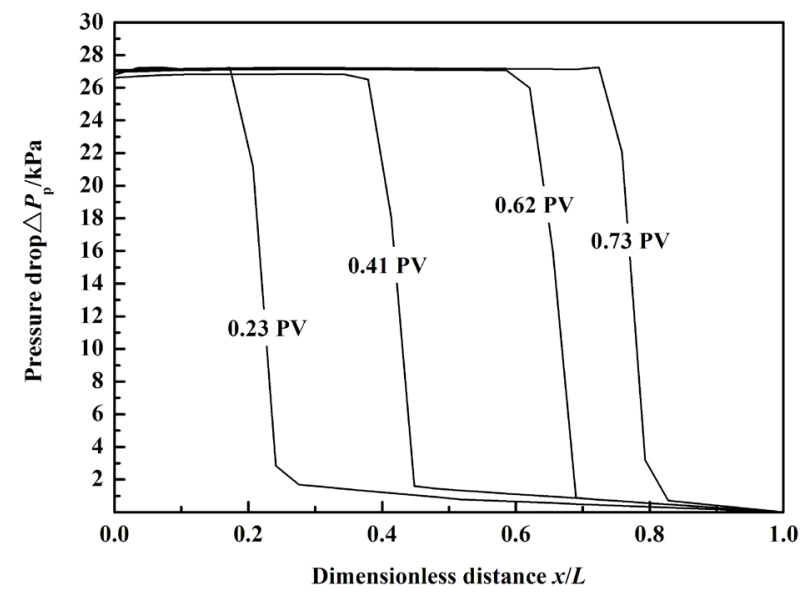

Figure 5. Profiles of the pressure drop $\Delta P_{\mathrm{p}}$ under the injection mode 2.

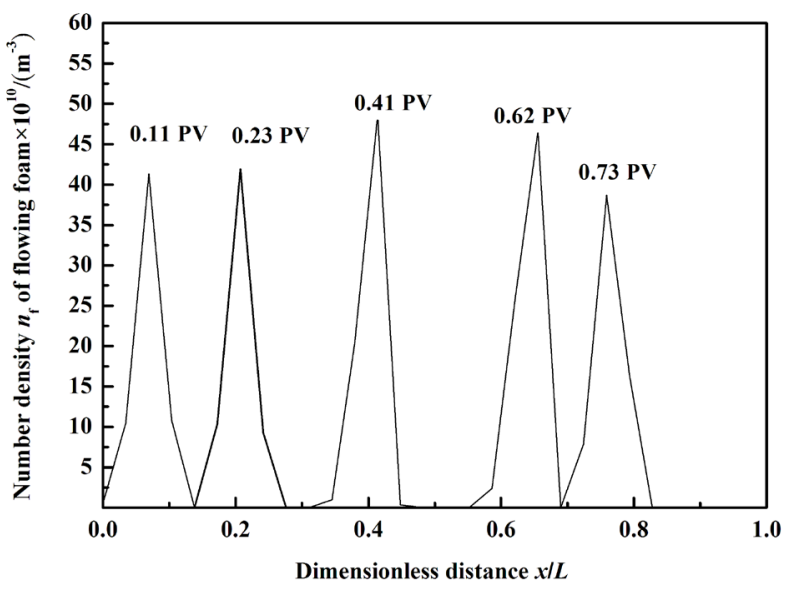

Figure 6. Profiles of the number density $n_{\mathrm{f}}$ of flowing foam under injection mode 2. 
downstream of flow front decreases slowly, which is due to the fine foam texture of flow front under injection mode 2.

In Figure 6, under the injection mode 2, the number density $n_{\mathrm{f}}$ of the flowing HPAM foam reaches the peak value sharply only at the flow front, and then the number density $n_{\mathrm{f}}$ of the flowing HPAM foam gets to be zero, which is because no sufficient liquid phase supplement leads the foam coalescence velocity at the flow front accelerating and the number density $n_{\mathrm{f}}$ of the flowing HPAM foam decreasing sharply under the injection mode 2.

\subsection{Injection Mode 3}

Under the injection mode 3 , the profiles of the liquid phase saturation $S_{\mathrm{p}}$, the pressure drop $\Delta P_{\mathrm{p}}$, the number density $n_{\mathrm{f}}$ of the flowing HPAM aqueous solution in the artificial sandstone core show as Figures 7-9.

In Figure 7, under the injection mode 3, the flow of the HPAM aqueous solution in the artificial sandstone core is a single phase fluid flow. Obviously, the liquid phase saturation $S_{\mathrm{p}}$ is 1 constantly.

In Figure 8, under the injection mode 3, the pressure drop $\Delta P_{\mathrm{p}}$ of the flowing HPAM aqueous solution changes linearly.

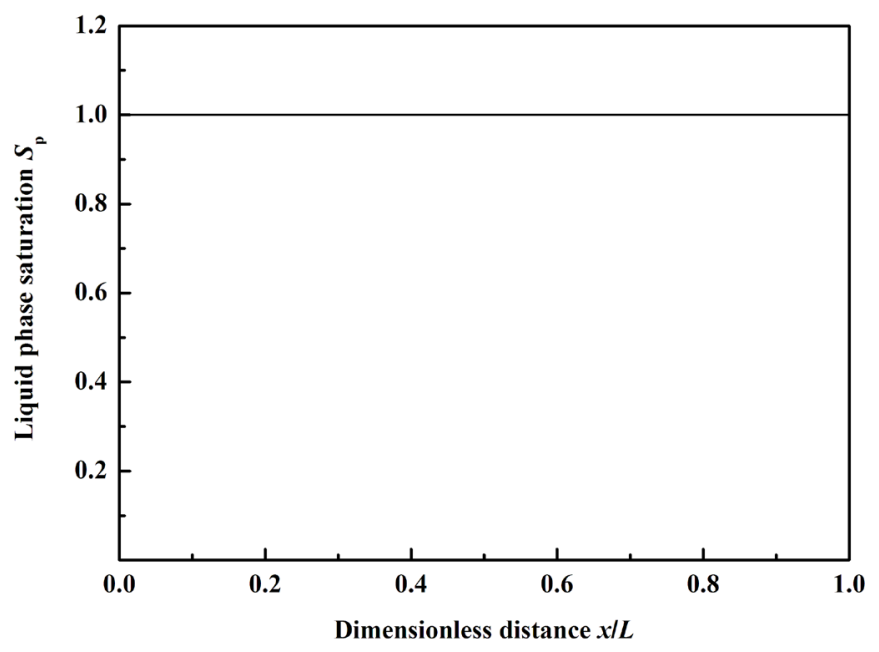

Figure 7. Profiles of the liquid phase saturation $S_{\mathrm{p}}$ under the injection mode 3.

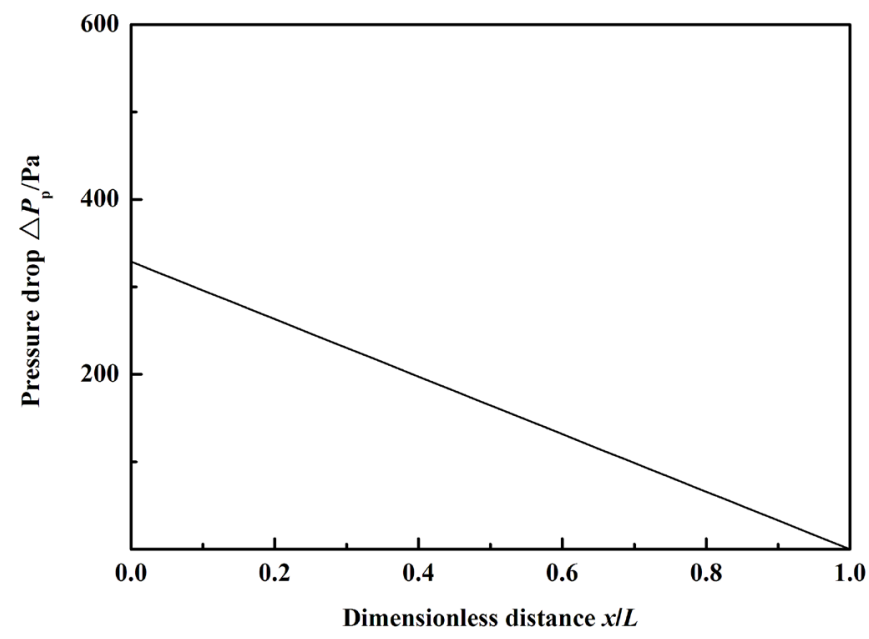

Figure 8. Profiles of the pressure drop $\Delta P_{\mathrm{p}}$ under the injection mode 3 . 


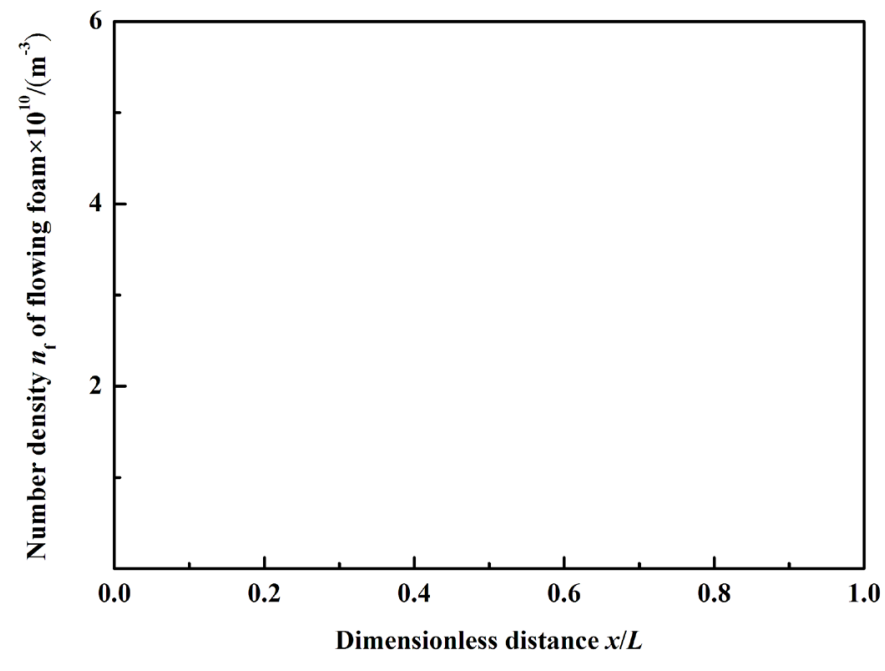

Figure 9. Profiles of the number density $n_{\mathrm{f}}$ of flowing foam under the injection mode 3 .

In Figure 9, under the injection mode 3, the number density $n_{\mathrm{f}}$ of the flowing HPAM aqueous solution is zero obviously.

\subsection{Comparisons of Injection Modes}

Among the three injection modes mentioned above, the pressure drop $\Delta P_{\mathrm{p}}$ of the flowing HPAM foam under the injection mode 1 is the biggest, which is because there is the highest number density $n_{\mathrm{f}}$ of the flowing HPAM foam under the injection mode 1 . Obviously, the flood efficiency of the injection 1 is the highest.

\section{Conclusions}

1) The mathematical models of the flow of the polymer foam in porous media under the three injection modes are established and the relevant numerical calculation methods are given.

2) The profiles of the liquid phase saturation, the pressure drop and the number density of the flowing HPAM foam with the dimensionless distance in the artificial sandstone core under the three injection modes are numerically calculated and analyzed.

3) Compared with the injection mode 2 and 3, HPAM foam flows in a piston-like fashion in the artificial sandstone core under the injection mode 1 and shows the biggest pressure drop. Obviously, flood efficiency is highest under the injection mode 1.

4) Based on the research results mentioned above, it can choose the better injection mode to reach the best flood efficiency in the polymer flooding engineering design according to the actual situation. Especially, in the injection mode 1 , it also needs the future study to continue working and researching for what factor influencing the flood efficiency most, such as the polymer type, concentration and so on.

\section{References}

[1] Shan, D. and Rossen, W.R. (2002) Optimal Injection Strategies for Foam IOR. SPE Journal, 9, 1-17.

[2] Steven, J.E., Harpole, K.J., Zornes, D.R. and Martin, F.D. (1992) CO2 Foam Field Verification Pilot Test at EVGSAU: Phase II-Foam Injection Design and Operation Plan. SPE Annual Technical Conference and Exhibition, Washington, DC, 4-7 October 1992, 115-128.

[3] Hou,Q.F., Zhu, Y.Y., Luo, Y.S. and Weng, R. (2012) Studies on Foam Flooding EOR Technique for Daqing Reservoirs after Polymer Flooding. Proceedings of the SPE Improved Oil Recovery Symposium, Tulsa, 14-18 April 2012, 1-11. http://dx.doi.org/10.2118/151955-ms

[4] Li, Z.Q., Zhou, G.H. and Zhou, Z.M. (2006) The Feasibility Studies of Polymer Foam Flooding in Gudao Oilfield. Proceedings of the SPE Asia Pacific Oil \& Gas Conference and Exhibition, Adelaide, 11-13 September, 1-8. 
http://dx.doi.org/10.2118/101189-ms

[5] Harsenhorst, R.M., Dharma, A.S., Andrianov, A. and Rossen, W.R. (2013) Extension of a Simple Model for Vertical Sweep in Foam SAG Displacement. Proceedings of the EAGE Annual Conference \& Exhibition Incorporating SPE Europec, London,10-13 June 2013, 1-11. http://dx.doi.org/10.2118/164891-ms

[6] Boeije, C.S. and Rossen, W.R. (2013) Fitting Foam Simulation Model Parameters to Data. Proceedings of the IOR 2013-17th European Symposium on Improved Oil Recovery, St. Petersburg, 16-18 April 2013, 1-16. http://dx.doi.org/10.3997/2214-4609.20142604

[7] Persoff, P., Radke, C.J., Pruess, K, Benson, S.M. and Witherspoon, P.A. (1991) A Laboratory Investigation of Foam Flow in Sandstone at Elevated Pressure. SPE Reservoir Engineering, 6, 365-372. http://dx.doi.org/10.2118/18781-PA

[8] Kovseck, A.R. (1994) Foam displacement in Porous Media: Experiment and Mechanistic Prediction by the Population Method. University of California at Berkely, Berkely.

[9] Zhao, W. (2015) Polymer Foam Transient Flow in the Porous Media. Northeast Petroleum University, Daqing.

[10] Bertin, H.J., Quintard, M.Y. and Castainier, L.M. (1998) Development of a Bubble-Population Correlation for Foam-Flow Modeling in Porous Media. SPE Journal, 3, 356-362. http://dx.doi.org/10.2118/52596-pa

[11] Garrouch, A.A. (1999) A Viscoelastic Model for Polymer Flow in Reservoir Rocks. Proceedings of the SPE Asia Pacific Oil and Gas Conference and Exhibition, Jakarta, 20-22 April 1999, 1-10. http://dx.doi.org/10.2118/54379-ms

[12] Falls, A.H., Musters, J.J. and Ratulowski, J. (1989) The Apparent Viscosity of Foams in Homogeneous Bead Packs. SPE Reservoir Engineering, 4, 155-164.

[13] Hirasaki, G.J. and Lawson, J.B. (1985) Mechanisms of Foam Flow in Porous Media: Apparent Viscosity in Smooth Capillaries. Society of Petroleum Engineers Journal, 25, 176-190. http://dx.doi.org/10.2118/12129-pa

[14] Aziz, K. and Settari, A. (1979) Petroleum Reservoir Simulation. Applied Science Publishers, London, 135-139.

[15] Leonard, B.P. (1984) Third Order Upwinding as a Rational Basis for Computational Fluid Dynamics. Proceedings of the Computational Techniques and Applications: CTAC-83, Sydney, 1983, 106-120. 